\title{
The Open Access Model, Trends and Opportunities in Accounting Research
}

\author{
Simone Domenico Scagnelli \\ Department of Management, University of Turin, Turin, Italy \\ Email: simone.scagnelli@unito.it
}

Received July 16, 2013; revised August 25, 2013; accepted September 6, 2013

Copyright (c) 2014 Simone Domenico Scagnelli. This is an open access article distributed under the Creative Commons Attribution License, which permits unrestricted use, distribution, and reproduction in any medium, provided the original work is properly cited. In accordance of the Creative Commons Attribution License all Copyrights (C) 2014 are reserved for SCIRP and the owner of the intellectual property Simone Domenico Scagnelli. All Copyright (C) 2014 are guarded by law and by SCIRP as a guardian.

\section{Dear Editor}

Nowadays academic scholars are increasingly facing the need of appropriate devices to disseminate knowledge and build up reputation; the "publish or perish" imperative stands out as a crucial warning in academia. Indeed, scientific publishing is a relevant device for validating and circulating new knowledge, as well as a means for rewarding researchers who can easily convert publications into salary, career promotions, new opportunities and research funding [1]. However, while the current economic downturn is affecting global businesses and leading to an overall increase of competitiveness, the marketplace of scholarly publications is facing a deep crisis because of the rise of journals' subscription prices and Universities' budget cuts and libraries' constraints. In the meantime, an increasing number of young scholars seek for sources and opportunities to disseminate research without economic constraints linked to copyrights and subscription fees.

Despite the related debate and argumentations of such issues, it seems that the "moral" component of research has overcome copyright and profit considerations by taking a distinctive direction toward a new way of research dissemination, the Open Access model (OA).

OA leverages on technological innovations, such as internet based web platforms, which allows scientific articles to be available and circulate at no cost for readers. OA adopts a commons-based system (i.e. free of entry without payment) in contrast with the existing enclosure-based system (i.e. reliant on exclusion against a price for access). Therefore, OA is a substantial useful effort in conforming to the theory that science must be open and accessible to everyone. Furthermore, the OA model eliminates exclusionary leverage over readers, which is instead a pivotal feature of the current publishing market [2] while scientific quality and standing can be ensured by ordinary editorial processes based on ri- gorous blind peer review, high visibility, prompt dissemination and involvement of recognised scholars as editorial boards' members.

OA can play a significant role in real scientific dissemination: openness is not restricting scholars to specific research boundaries, in contrast with the enclosed publication system which relies on mainstream research topics that usually drive subscriptions and citations [3].

Therefore, in the last decade an increasing number of OA publications have been released, leading today's total figure up to ten thousands internet based open journals. The leading disciplines among the available OA journals are Medicine, Education and Computer Sciences which reach one third of the total. Although Business and Management subjects are covered by more than 400 OA journals, a figure which increases every month, only few journals are specifically focused and designed to disseminate Accounting research. On a worldwide basis, the current number of OA publications specifically devoted to Accounting hardly reaches a total number of 40 and, among them, the majority are published in South America and use Portuguese and Spanish as main languages of publication.

Moreover, the majority of such OA journals are affiliated or published by public or private institutions which can limit the topic and, therefore, the publication chance of the proposed articles. Yet, mainstream accounting research is dogmatizing an image of efficient markets in which investors make rational decisions by evaluating all risks and returns of alternatives thanks to accounting and financial disclosure. The concept of "economic man" based on the rational behavior of users is too simplistic [4]. It is high time that accounting literature moves away from narrow mainstream approaches and adopts a much broader research perspective based on the dissemination of new frameworks and innovative advances.

Therefore, the role played by a journal such as the 
Open Journal of Accounting (OJAcct) is becoming increasingly significant and strategic. OJAcct is one of the few OA journal specifically designed to publish accounting research in English, allowing scholars to reach appropriate dissemination of their research. The high standing and experience of the Publisher, the fair peerreview process and the absence of a mainstream focus, allows OJAcct's authors to build up and strengthen their reputation within the scientific community. Because OJAcct is dedicated to the latest advancement of all areas of accounting, it can really be the most suitable dissemination device for productive and innovative accounting scholars.

\section{REFERENCES}

[1] G. B. Ramello, “Copyright and Endogenous Market
Structure: A Glimpse from the Journal Publishing Market," Review of Economic Research on Copyright, Vol. 7, No. 1, 2010, pp. 7-29.

[2] M. Migheli and G. B. Ramello, "Open Access, Social Norms and Publication Choice," European Journal of Law and Economics, Vol. 35, No. 2, 2013, pp. 149-167. http://dx.doi.org/10.1007/s10657-013-9388-X

[3] J. Finch, "Accessibility, Sustainability, Excellence: How to Expand Access to Research Publications,” Research Information Network, London, 2012.

[4] A. Hellmann and S. D. Scagnelli, "Behavioral Accounting: Shifting Away from Techniques to People,” In: D. W. Nelson, Ed., Advances in Business and Management, Vol. 3, Nova Science Publishers, New York, 2011, pp. 153156. 